\title{
EDUCAÇÃO ESPECIAL EM UMA PERSPECTIVA INCLUSIVA: SABERES EM CONSTRUÇÃO
}

\section{EDUCACIÓN ESPECIAL EN UNA PERSPECTIVA INCLUSIVA: CONOCIMIENTOS EN CONSTRUCCIÓN}

\author{
SPECIAL EDUCATION IN AN INCLUSIVE PERSPECTIVE: KNOWLEDGE UNDER \\ CONSTRUCTION
}

\author{
Mirlene Ferreira Macedo DAMÁZIO ${ }^{1}$
}

RESUMO: Apresentamos nesta edição uma publicação científica, capaz de contribuir com a temática: Educação especial em uma perspectiva inclusiva: saberes em construção, visando organizar trabalhos que acompanham esse assunto. Essa matéria tem sido investigada por grupos de pesquisadores em universidades brasileiras, vislumbrando a inserção com igualdade e equidade das pessoas com deficiência. O tema é polêmico e envolve vários conflitos conceituais e operacionais, logo, torna-se importante pensar e repensar o contexto histórico, as necessidades pedagógicas, as diferenças individuais e coletivas dessas pessoas e os atores envolvidos no processo. Desses objetos de estudos surgem as contribuições desta publicação. A edição foi organizada com 14 artigos, envolvendo o ensino, a pesquisa e a extensão da graduação e pós-graduação, bem como experiências de rede de ensino públicas.

PALAVRAS-CHAVE: Educação Especial. Inclusão. Necessidades pedagógicas.

RESUMEN: Presentamos en esta edición una publicación científica, capaz de contribuir al tema: Educación especial desde una perspectiva inclusiva: conocimiento en construcción, con el objetivo de organizar trabajos que acompañen a esta asignatura. Esta asignatura ha sido investigada por grupos de investigadores de universidades brasileñas, con cediendo la inserción con igualdad y equidad de personas con discapacidad. El tema es controvertido e involucra varios conflictos conceptuales y operativos, por lo que es importante pensar y repensar el contexto histórico, las necesidades pedagógicas, las diferencias individuales y colectivas de estas personas y los actores involucrados en el proceso. De estos objetos de estudios surgen las aportaciones de esta publicación. La edición se organizó con 14 artículos, que involucran la enseñanza, investigación y extensión de programas de pregrado y posgrado, así como experiencias de redes públicas de enseñanza.

PALABRAS CLAVE: Educación Especial. Inserción. Necesidades pedagógicas.

ABSTRACT: We present in this edition a scientific publication, capable of contributing to the theme: Special education in an inclusive perspective: knowledge under construction, aiming to organize works that accompany this subject. This subject has been investigated by groups of researchers in Brazilian universities, envisioning the insertion with equality and equity of people with disabilities. The theme is controversial and involves several conceptual and

1 Universidade Federal da Grande Dourados (UFGD), Dourados - MS - Brasil. Doutora. Professora da Faculdade de Educação da UFGD. Pesquisa Passo a Passo. ORCID: http://orcid.org/0000-0001-7449-2261. Email: psmirlenefm@gmail.com 
operational conflicts, so it becomes important to think and rethink the historical context, pedagogical needs, individual and collective differences of these people and the actors involved in the process. From these objects of studies arise the contributions of this publication. The edition was organized with 14 articles, involving teaching, research and extension of undergraduate and graduate programs, as well as public teaching network experiences.

KEYWORDS: Special Education. Inclusion. Pedagogical needs.

\section{Apresentação}

A inclusão das pessoas com deficiência no sistema educacional faz parte das lutas e suas conquistas ao longo da história, no qual foram capazes de superar barreiras, limites e marcar seus potenciais. Hoje, eles dizem "Nada sem nós". Essa frase é impactante e demonstra que não aceitam que ninguém fale por eles, são protagonistas de suas histórias.

O acesso e a permanência das pessoas com deficiência no sistema educacional em seus vários níveis e modalidades significam superação de barreiras e obstáculos, no qual o elemento principal de combate é o preconceito, a discriminação e a eliminação do capacitismo. Eles desejam ser inseridos a partir de seus potenciais e qualidades naturais, e não apenas por obrigatoriedade de leis. Para tanto, é preciso eliminar as barreiras físicas, arquitetônicas, urbanísticas, comunicativas, pedagógicas e atitudinais, promovendo a acessibilidade, em síntese, realizar o mote da inclusão.

As leis brasileiras têm afirmado o direito de educação para todas as pessoas. Diante do exposto, vimos que atualmente existe amparo legal para o acesso e a inclusão das pessoas com deficiência da educação básica ao ensino superior, garantindo permanência, igualdade de oportunidades com equidade. Contemplar as diversidades e diferenças, disponibilizar recursos financeiros, físicos e humanos para atender as necessidades básicas é compromisso atual das políticas públicas de inclusão, envolvendo a educação especial, é preciso atitude dos gestores e professores. Entretanto, os desafios são imensos em virtude do desrespeito às diferenças e potenciais humanos. A marca ainda legitimada, infelizmente, é do déficit, da falta e da falha e assim precisamos combater essa realidade com pesquisas e estudos que vislumbram marcar a possibilidade e ajudar a enfrentar os desafios existentes.

No primeiro artigo, as autoras Denise Mesquita de Melo Almeida e Hanmi Cedeño Lima nos levam a refletir sobre as condições de trabalho dos profissionais da psicologia na educação especial. Os resultados apontaram que os psicólogos secundarizam essa escolha de atuação profissional e apresentam fragilidade em sua formação para atuar na área. Salientam que a formação continuada, articulada à troca de experiências, sob a perspectiva inclusiva, tem permitido a ressignificação e o engajamento na área. 
No artigo de Léa Geller, Marli da Costa Gonçalves e Luciene Barbosa Vitor Lima, é relatada a história da construção da educação especial no município de Caarapó-MS, enfatizando as vivências, as experiências e as práticas desenvolvidas por meio do Atendimento Educacional Especializado de 2003 a 2018 em busca de uma perspectiva inclusiva dos alunos com deficiência.

O terceiro artigo de Ana Cristina Silva Soares, Daniele Kelly Lima de Oliveira e Maria Gorete de Sousa, sobre Reflexões a partir da percepção dos discentes sobre inclusão e cotas para estudantes com deficiências no ensino superior, analisa como a inclusão vem sendo marcada por desigualdades e ideias equivocadas, comprometendo o acesso e a permanência nos cursos de graduação. Os resultados evidenciam que ações podem colaborar com a inclusão de estudantes com deficiências no Ensino Superior.

No quarto artigo, de Aurélia Teodoro da Cruz e Paloma Alinne Alves Rodrigues, as autoras revelam os desafios da inclusão das pessoas com deficiência nas universidades. $\mathrm{O}$ trabalho investigou e analisou a inclusão e a permanência dos estudantes com deficiência em uma instituição mineira. Constataram que ações relacionadas à aceitação das diferenças, aliadas à formação de professores com práticas inclusivas, auxiliarão em muito a transformação desse espaço educacional universitário.

O quinto artigo, de Maria Isabel de Araújo, sobre altas habilidades na educação infantil, envolvendo um relato de caso de uma instituição escolar do município de Uberlândia, mostra-nos como saber/identificar as características e os comportamentos de superdotação/altas habilidades. O relato indicou, a partir do caso estudado na educação infantil, comportamentos com características de altas habilidades do tipo acadêmico e produtivo-criativa e potencial elevado nas áreas das inteligências linguística, espacial, lógicomatemático. O estudo ajudou a compreender o desenvolvimento do aluno e apoiou o professor na gestão pedagógica de suas aulas.

Já o sexto artigo, de Carla Barbosa Alves e Maria Irene Miranda, descreve-nos e analisa a proposta de trabalho do Atendimento Educacional Especializado das escolas municipais do município de Uberlândia-MG. Em seus resultados, a pesquisa delineou a necessidade da interlocução entre professores do AEE e da sala/classe comum, bem como uma formação continuada dos professores de acordo com a perspectiva inclusiva.

$\mathrm{O}$ artigo sétimo, Neurociência na educação especial: dos neuromitos às práticas pedagógicas baseadas em evidências, escrito por Daniel Traina Gama e Marcela de Castro Ferracioli, apresentou-nos uma discussão sobre as fundamentações lógica e teórica que subsidiam a disciplina de neurociência do curso de Especialização em Educação Especial da Faculdade de Educação/UFGD. Verificou-se que professores têm crença nos neuromitos e 
isso os prejudica realizar suas práticas pedagógicas, bem como precisam relacionar esses estudos da neurociência aos princípios da educação especial.

O oitavo artigo, de Rosimar Bortolini Poker, Beatriz Aparecida Barboza do Nascimento e Claudia Regina Mosca Giroto, fala-nos que a educação especial não assume mais o caráter substitutivo da sala regular, mas torna-se um serviço pedagógico complementar. Também investigou a compreensão que professores especialistas regentes de Salas Multifuncionais têm da educação inclusiva e especial e de sua formação. Constatou-se que a maior parte dos professores conhece a diferença entre educação especial e inclusiva e reconhece que sua formação é precária.

No tocante ao nono artigo, Educação especial no município de Naviraí-MS: história, desdobramentos e desafios para a inclusão escolar, de Felipe Alves Barbosa e Ilma Regina Castro Saramago de Souza, ele nos aponta que, desde os primeiros atendimentos aos alunos com deficiência, a educação especial no município de Naviraí teve vários avanços, mas constatou-se a carência de formação e de qualificação para os professores. Entretanto, salienta-se que o município tem buscado estratégias para que a inclusão escolar seja efetivada.

O décimo artigo, de Cassiano Caon Amorim, Katiuscia C. Vargas Antunes e Mylene Cristina Santiago, Inclusão no ensino superior: um processo em pauta na Universidade Federal de Juiz de Fora, relata-nos e faz reflexões sobre como os processos de inclusão têm sido desenvolvidos nesta universidade. Os resultados apontam que esta vem desenvolvendo processos e experiências sobre culturas, políticas e práticas de inclusão na comunidade, sendo os estudantes os protagonistas principais.

No que diz respeito ao décimo primeiro artigo, Alunos com autismo na escola comum: eis a questão de Ivonete Ferreira da Silva e Mirlene Ferreira Macedo Damázio, somos levados a refletir sobre as dificuldades na educação escolar. Estudou-se a trajetória histórica esclarecendo quais os obstáculos apontados para incluir o aluno com autismo na escola comum. Concluiu-se o seguinte: é necessária a mudança de concepção dos currículos escolares; há a necessidade de cursos para a formação continuada de professores; o professor precisa compreender o perfil de aluno com autismo; e a organização do corpo docente precisa ser diferente, envolvendo professores e apoio escolar.

O décimo segundo artigo, de Magali Dias de Souza, Luiz Alberto Ferreira e Filomena Lucia Gossler Rodrigues da Silva, discorre sobre Tecnologia assistiva cães-guia no Brasil: uma ação política orientada à inclusão social de pessoas com deficiência visual, implantada pelo Instituto Federal Catarinense em Camboriú. Os autores contextualizam e analisam a 
política governamental tecnologia assistiva cães-guia, destacando seu impacto na vida dos usuários com deficiência visual.

No artigo décimo terceiro, Educação em Ciências e a inclusão de alunos com deficiência intelectual: entraves no ensino de Física, de Mariangela Dias Alves e Paloma Alinne A. Rodrigues, demonstrou-se que existem lacunas na formação do professor do ensino regular, bem como a existência de barreiras atitudinais, envolvendo preconceitos e estigmas com relação aos estudantes.

No último artigo, Josiane Fujisawa Filus de Freitas e Paulo Ferreira de Araújo abordam a percepção dos professores sobre a organização do Atendimento Educacional Especializado em um município, constatando que o professor do atendimento foca seu trabalho nas questões individuais ao estudante, seguindo os modelos da educação especial e se sentindo parte do todo da escola.

A partir desta apresentação, esperamos que os artigos deste dossiê contribuam com os profissionais e pesquisadores da área de educação especial em seu pensar e fazer da práxis pedagógica, favorecendo o desenvolvimento dos estudantes com deficiência.

\section{Como referenciar este artigo}

DAMÁZIO, Mirlene Ferreira Macedo. Educação especial em uma perspectiva inclusiva: saberes em construção. Doxa: Rev. Bras. Psico. e Educ., Araraquara, v. 21, n. 2, p. I-V, jul./dez. 2019. e-ISSN: 2594-8385. DOI: https://doi.org/10.30715/doxa.v21i2.13622

Submetido em: 20/02/2019

Aprovado em: 20/07/2019

Publicado em: 01/08/2019 